\title{
Highly efficient solar steam generation of low cost TiN/bio-carbon foam
}

\author{
Dongfang Guo ${ }^{1}$ and Xiuchun Yang ${ }^{1,2^{*}}$
}

\begin{abstract}
The use of solar energy to produce steam is an effective method to purify sewage or seawater. Herein, we deposited TiN nanoparticles (NPs) on a piece of carbonized wood as a new type of double layer material for solar water evaporation. TiN NPs possess better stability, lower cost, lower toxicity and wider and stronger optical absorption than the previously reported photo-thermal conversion (PTC) materials, such as plasmonic metals, carbon-based materials and semiconductor nanomaterials. The amounts of TiN NPs and the thicknesses and types of the substrates have important influences on water evaporation rates and solar-vapor conversion efficiency. A solar-vapor conversion efficiency of 92.5\%, the highest efficiency in the reported wood-based PTC materials, is obtained under 1-sun simulated solar irradiation. In addition, the TBCF hybrid materials (TiN NPs on biocarbon foam) exhibit good reusability.
\end{abstract}

Keywords: TiN nanoparticles, bio-carbon foam, double layer structure, photo-thermal conversion, solar-vapor conversion efficiency

\section{INTRODUCTION}

Solar energy has attracted extensive public attention because of its inexhaustibility, non-pollution, no need to transport, and no influence to natural balance. Utilizing solar energy efficiently is a key to energy crisis and environmental pollution. At present, the ways of using solar energy can be divided into three categories: photoelectric conversion [1-3], photochemical conversion [4-6] and photo-thermal conversion (PTC). Solar vapor generation can directly transfer solar energy to heat. It has attracted tremendous attention due to great application potential in energy conversion [7], seawater desalination [8,9], sewage treatment [10], liquid-liquid separation $[11,12]$ and sterilization and hygiene systems [13]. In order to enhance solar evaporation conversion efficiency, it is necessary to combine high-efficiency PTC materials with a substrate for heat insulation and liquid supply. PTC materials for heating and evaporating water include plasmonic metals [14-18] and ceramic nanomaterials [19], carbon-based materials [20-25] and semiconducting nanomaterials $[26,27]$. For instances, Chen et al. [28] reported a dualfunctional asymmetric plasmonic structure formed by silver nanoparticles and porous templates. Wang et al. [29] dispersed $\mathrm{Au}$ nanoparticles (NPs) on the mixed cellulose ester (MCE) filter membrane for water evaporation. $\mathrm{Xu}$ et al. [30] decoupled solar absorption and water pumping function into different layers, an upper carbon black nanoparticles coating poly(methylmethacrylate) layer and a lower hydrophilic polyacrylonitrile layer, to achieve a stable and efficient desalination. Reduced graphene oxide (GO) sheets were also dispersed on MCE by Wang and his coworkers [31] to obtain efficient evaporation efficiency. Li et al. [32] combined a 3D cone absorber of GO with a one dimensional (1D) water path to enhance the evaporation area and rate. $\mathrm{Hu}$ et al. [33] and Ren et al. [34] respectively used GO-based aerogels and hierarchical graphene foam for efficient solar steam generation. Recently, we reported the hierarchical TiN nanotube mesh on glass-fiber cotton for solar water evaporation with $85.36 \%$ efficiency under $2.5 \mathrm{~kW} \mathrm{~m}^{-2}$ simulated solar irradiation [19]. Until now, the highest efficiency under 1 Sun is $94 \%$ using a hierarchically nanostructured gel based on polyvinyl alcohol (PVA) and polypyrrole (PPy) [35].

Wood is also adopted as PTC material for solar-thermal water evaporation because of its various advantages such as low cost, nontoxicity, superior stability in water, natural hydrophilicity, numerous aligned micro-channels for fast water transportation, low thermal conductivity along the channel direction and excellent buoyancy property [36-40]. Liu et al. [41] combined GO with wood to obtain

\footnotetext{
${ }^{1}$ School of Materials Science and Engineering, Tongji University, Shanghai 201804, China

${ }^{2}$ Key Laboratory of Advanced Civil Engineering Materials (Tongji University), Education of Ministry, Shanghai 201804, China

* Corresponding author (email: yangxc@tongji.edu.cn)
} 


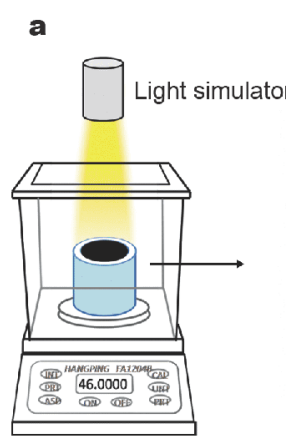

b

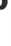

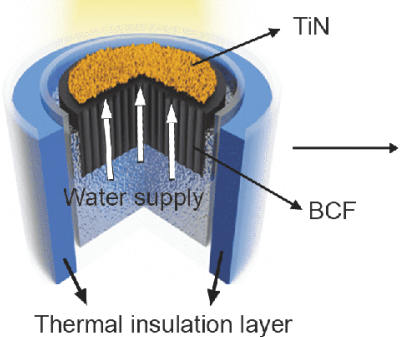

c

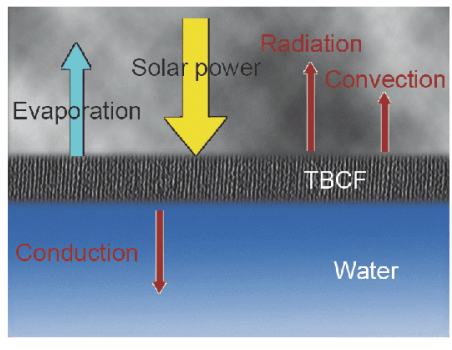

Figure 1 (a) Setup for the measurement of solar water evaporation performance; (b) schematic diagram of solar water evaporation process for the sample TBCF; (c) heat transfer diagram in TBCF during vapor generation process.

a solar-thermal efficiency of $\sim 83 \%$ under 12 -Sun. Xue et al. [40] reported that the flame-treated wood has a solar-thermal efficiency of $72 \%$ under 1-Sun irradiation. Chen et al. [42] prepared carbon nanotube-modified flexible wood membrane and obtained a high efficiency of $81 \%$ under 1-Sun. Zhu et al. [43] prepared a novel type of plasmonic wood exhibiting a high solar-thermal conversion efficiency of $85 \%$ under 10 -Sun illumination. Xu et al. [44] carbonized natural mushrooms and achieved $78 \%$ conversion efficiency under $1-\mathrm{Sun}$. $\mathrm{Li}$ and coworkers [45] designed an elegant structure formed by cotton cores and plant cellulose coated with carbon black NPs, which can exploit environmental energy to enhance the performance of an interfacial solar vapor generation.

Since TiN is a plasmonic material with a wider and stronger absorption spectrum, lower toxicity and better stability compared to the traditional PTC materials $[46,47]$, we deposited TiN NPs on a piece of carbonized wood as a new type of double layer material for solar water evaporation. The hybrid material possesses good stability, low cost and low toxicity with a solar-vapor conversion efficiency of $92.5 \%$ under only 1-Sun simulated solar irradiation, the highest efficiency among the reported wood-based PTC materials.

\section{EXPERIMENTAL SECTION}

Bio-carbon foam (BCF) was fabricated by a simple carbonization of the beech wood. Beech logs were cut into small round chips with a diameter of $40 \mathrm{~mm}$ and a thickness of $10 \mathrm{~mm}$. The cutting direction was perpendicular to the growth direction. These wood chips were then polished with 320 meshes of sandpaper to obtain clean and smooth surfaces. Afterwards, they were carbonized in a muffle furnace at $320^{\circ} \mathrm{C}$ for $70 \mathrm{~min}$ under a hypoxic condition.
A simple syringe coating method was adopted to deposit TiN NPs on BCF surface. $10 \mathrm{mg}$ TiN nanopowder with a mean diameter of $20 \mathrm{~nm}$ was dispersed into $10 \mathrm{~mL}$ ethanol by magnetic stirring for $30 \mathrm{~min}$ at room temperature. After ultrasonic dispersion for another $30 \mathrm{~min}$, different volumes of dispersions of $0.5,1.0,1.5,2.0$ and $4.0 \mathrm{ml}$ were coated on BCF surface, respectively. During the coating process, the sample surface was continuously dried by a hair dryer to accelerate the evaporation of ethanol.

Fig. 1a gives a setup diagram for the measurement of solar water evaporation performance. A nested cubic container was stored on an electric balance to measure the weight of evaporated water. For each run, distilled water was filled into the container where the sample floated on the water surface. A 500W Xenon lamp was used to simulate the solar irradiation on the sample, 1 Sun irradiation intensity was obtained by adjusting the distance between the lamp and the sample. The intensity can be measured by QTS-4 all-weather optical radiation recorder (Jinzhou Sunshine Technology Company, China). In certain time interval, the weight of water in the container was recorded automatically. At the same time, K-type thermocouple was used to measure the temperatures of surface and bulk water. Fig. $1 \mathrm{~b}$ and $\mathrm{c}$ give the solar water evaporation process and heat transfer diagram. The heat loss involves the radiative and convective heat losses to the ambience and the conductive heat loss to the bulk water. The calculated total heat loss accounts for $11 \%$ of all irradiation energy as shown in Supporting information, namely, $89 \%$ solar irradiation energy is used to evaporate water, which is a little lower than the experimental value of $92.5 \%$ because of the uncertainty of some parameters such as $\varepsilon, h$ and $C$ and the measurement error of the evaporation rates $r$. 

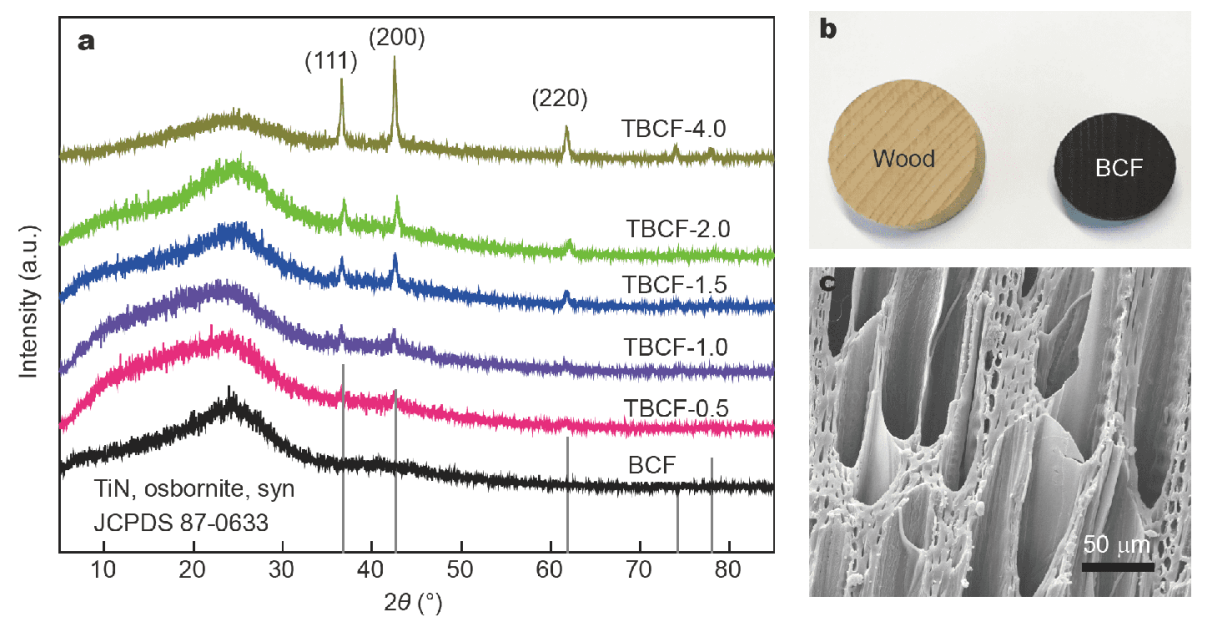

Figure 2 (a) XRD patterns of BCF and TBCF series; (b) optical images of wood and BCF; (c) SEM image of BCF.

The phase compositions of these samples were measured by a Rigaku D/Max 2400 X-ray diffractometer (XRD) equipped with graphite monochromatized $\mathrm{Cu} \mathrm{Ka}$ radiation $(\lambda=0.15406 \mathrm{~nm})$. Microstructures of these samples were characterized by a field emission scanning electron microscopy (FESEM, Quanta 200 FEG) with energy disperse spectroscopy (EDS). UV-vis-NIR absorption spectra of these samples were recorded on UV4100 UV-Vis-NIR diffuse reflectance spectroscopy (HITACHI, Japan) with an integrating sphere attachment.

\section{RESULTS AND DISCUSSION}

Bio-carbon foam (BCF) was fabricated by a simple carbonization of the beech wood. After carbonization, BCF becomes black as shown in Fig. $2 \mathrm{~b}$ and has a weight loss of $\sim 60 \%$ and an area decrease of $\sim 40 \%$ due to the evaporation of the combined water and the thermal decomposition of lignin, cellulose and hemicellulose. The apparent porosity and the water absorption of the asprepared $\mathrm{BCF}$ are $80 \%$ and 1.39 , respectively, much higher than the corresponding values of $38 \%$ and 0.51 of the pristine wood, indicating significant enhancements in water supply properties for the BCF. The XRD pattern of the BCF in Fig. 2a indicates that it is composed of amorphous carbon. Fig. $2 c$ shows SEM image of the BCF which exhibits a hierarchically microporous structure with a large number of aligned vertical channels. These channels with diameters from 5 to $50 \mu \mathrm{m}$ can transport water upwards from the bottom of the device effectively due to the capillary effect.

TiN NPs were deposited on the BCF by a simple syringe coating method. The as-prepared samples with dif- ferent TiN amounts of $0.5,1.0,1.5,2.0$ and $4.0 \mathrm{mg}$ were marked as TBCF-0.5, TBCF-1.0, TBCF-1.5, TBCF-2.0 and TBCF-4.0 respectively. Their XRD patterns in Fig. 2a indicate obvious TiN diffraction peaks (JCPDS 87-0633), and the peak intensity become stronger with increasing dosage of TiN NPs.

Fig. 3 shows SEM images and the corresponding EDS spectrum of TBCF series. Fig. 3a indicates that TiN NPs sporadically distributed on the rough surface of the BCF when TiN deposition amount is $0.5 \mathrm{mg}$. The coverage of TiN NPs on the BCF increases with increasing TiN deposition amount as shown in Fig. 3b-e. Fig. 3d indicates that TiN NPs almost completely cover the surface of the BCF when TiN deposition amount is $2 \mathrm{mg}$. Further increasing TiN deposition amount up to $4 \mathrm{mg}$ leads to a dense covering with a thickness of about $5 \mu \mathrm{m}$ as shown in Fig. $3 \mathrm{~h}$. The cross-section image and the corresponding EDS spectrum of TBCF-2.0 in Fig. $3 \mathrm{f}$ and $g$ indicate that a few TiN NPs also infiltrate into the inner channels of the BCF.

In order to quantify the absorption performance of TBCF series with different TiN content, their diffusive reflection spectra were measured over a wavelength range of $200-2,000 \mathrm{~nm}$. It is clearly in Fig. $4 \mathrm{a}$ that the BCF has a stronger optical absorption than the pristine wood in the wavelength range of $400-2,000 \mathrm{~nm}$. The BCF possesses the unique electronic structure of carbon that makes it able to absorb the sunlight and convert it into heat efficiently and its rough porous surface that extends the light-matter interaction length, increases the light collection and reduces the light reflection. When TiN NPs are deposited on the BCF, the hybrid material exhibits an 

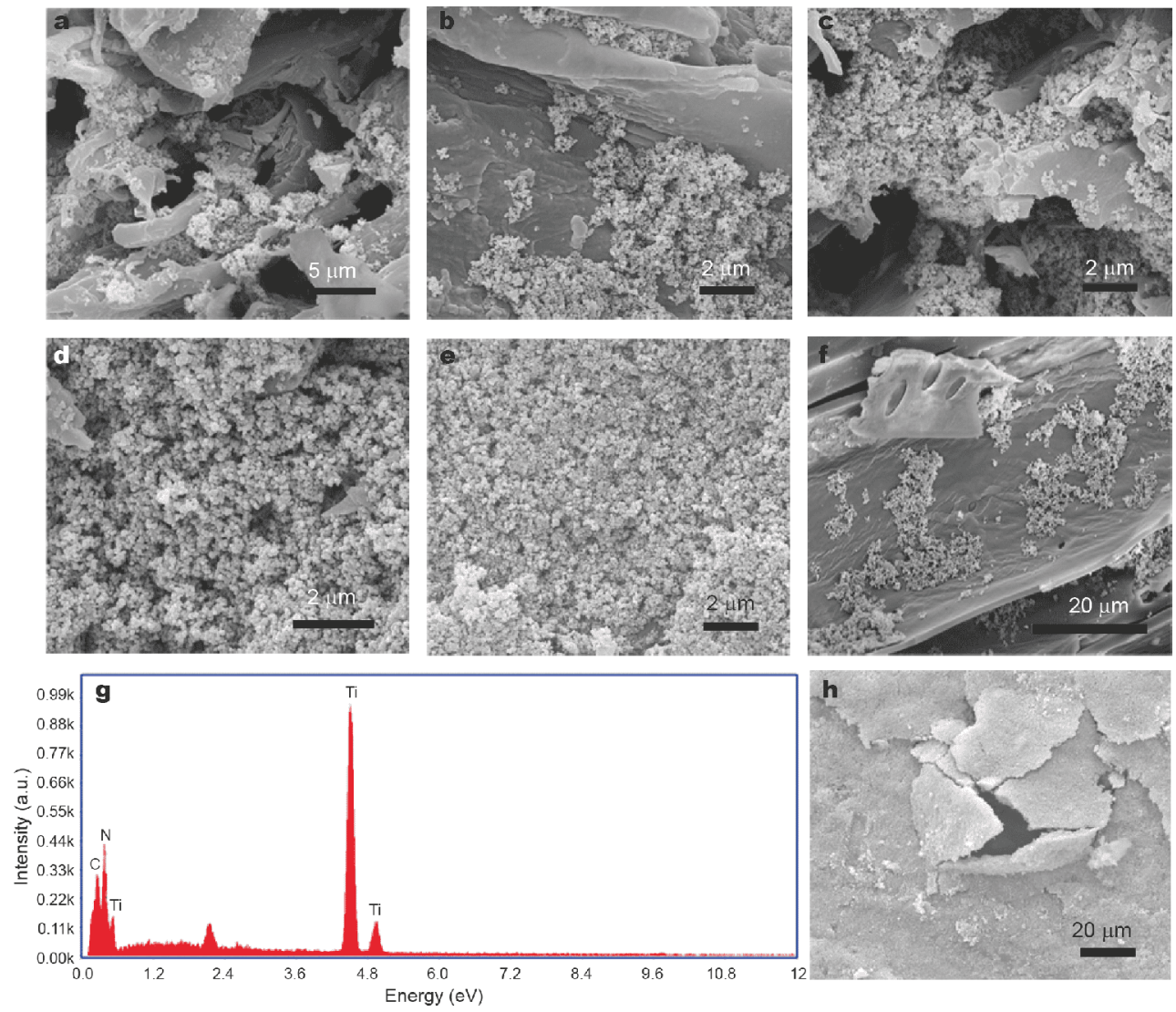

Figure 3 SEM images of TBCF series: TBCF-0.5 (a), TBCF-1.0 (b), TBCF-1.5 (c), TBCF-2.0 (d), TBCF-4.0 (e) and (h); cross section image (f) and EDS spectrum (g) of TBCF-2.0.

increasing optical absorption in $400-2,000 \mathrm{~nm}$, and the absorption increases with increasing TiN deposition amount. Fig. $4 \mathrm{~b}$ indicates that the weighted mean solar absorption of the BCF and TBCF-1.5 are $92 \%$ and $96 \%$ calculated by Equation (1) [27], respectively, which means that the hybrid material has a higher absorbance than the BCF over the entire solar spectrum.

$$
A=\frac{\int(1-R) S \mathrm{~d} \lambda}{\int S \mathrm{~d} \lambda},
$$

where $A$ is the solar absorption, $R$ is the reflectance of the sample, $S$ is solar spectral irradiance $\left(\mathrm{W} \mathrm{m}^{-2} \mathrm{~nm}^{-1}\right), \lambda$ is the wavelength $(\mathrm{nm})$. Here, the $(1-R) S$ represents the absorption of solar spectral irradiance.

To demonstrate the solar-thermal property of TBCF series, we investigated their water evaporation performance and the reusability as shown in Fig. 5. For the experiment of the reusability, the irradiance time is $3 \mathrm{~h}$ for each cycle, and after each cycle, the samples were taken out and completely dried. As a reference, the water evaporation experiments with and without TBCF were also carried out. Note that the BCF can float on water and get saturated with water automatically due to its low density and good hydrophilicity. Once $1 \mathrm{~kW} \mathrm{~m}^{-2}$ simulated sun light irradiated on these samples, vapor generated immediately with the mass changed with time as shown in Fig. $5 \mathrm{a}$ and c. The solar-vapor conversion efficiency $(\eta)$ can be calculated by Equation (2) [19].

$$
\eta=Q_{\mathrm{e}} / Q_{\mathrm{s}},
$$

where $Q_{s}$ is the incident light power $\left(1 \mathrm{~kW} \mathrm{~m}^{-2}\right)$ and $Q_{\mathrm{e}}$ is the water evaporation power, which can be estimated by Equation (3)

$$
Q_{\mathrm{e}}=H_{\mathrm{v}} \times \mathrm{d} m / \mathrm{d} t=H_{\mathrm{e}} \times r,
$$

where $H_{\mathrm{v}}$ is the evaporation heat of water $\left(\sim 2,260 \mathrm{~kJ} \mathrm{~kg}^{-1}\right), m$ is the evaporated water mass, $t$ is time, and $r$ is the evaporation rate of water obtained by linearly fitting these data between 120-150 min because $r$ rises with irradiance time and becomes relatively stable after 120 min during the evaporation experiment.

Clearly, compared with the control case without any 

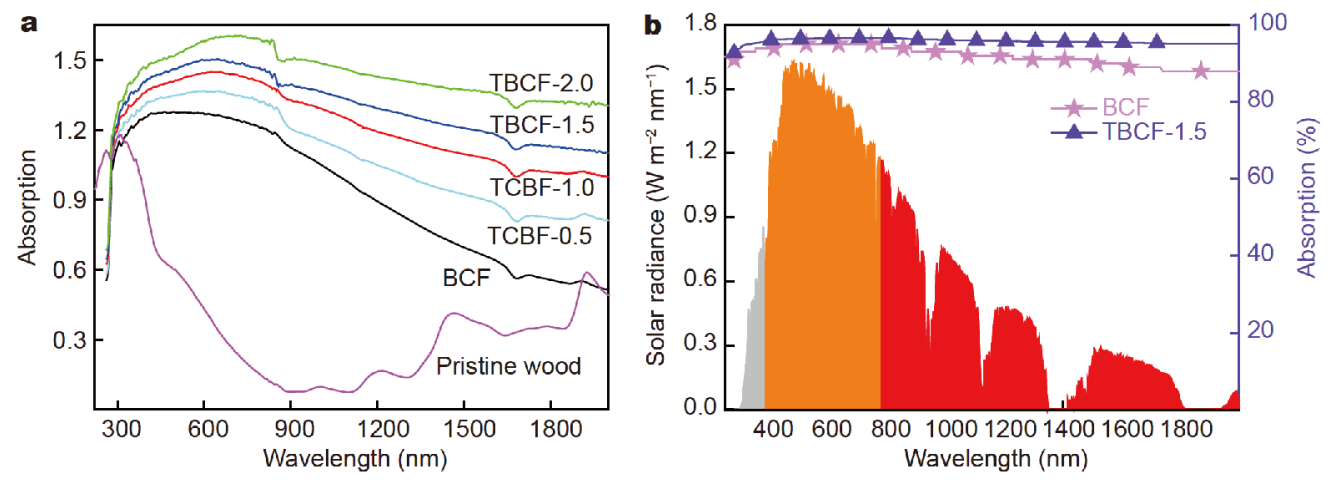

Figure 4 (a) UV-vis-NIR absorption spectra of TBCF series and pristine wood in the wavelength range from 200 to 2,000 nm; (b) solar spectral irradiance (AM $1.5 \mathrm{G}$ ) (left hand side axis) and absorption of BCF and TBCF-1.5 (right hand side axis), weighted by standard AM 1.5 G solar spectrum.
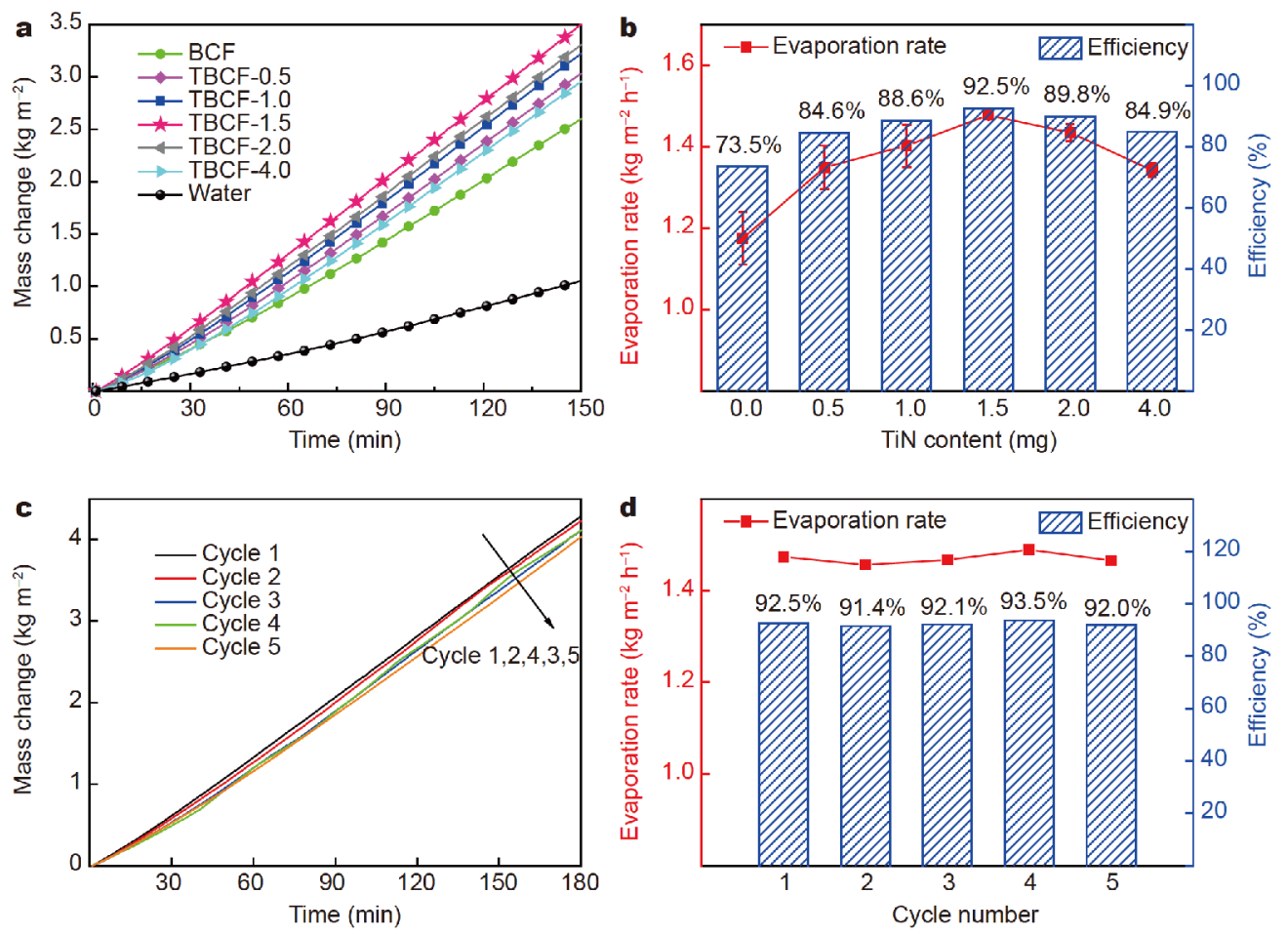

Figure 5 Solar water evaporation performance of TBCF under 1-sun with pure water as the control (a); (b) corresponding evaporation rates (red square) and solar-vapor conversion efficiency (blue column) of TBCF, each error bar represents the deviation from 3 data points. Water mass changes with time for different cycle numbers (c), and the corresponding evaporation rates (red square) and solar-vapor conversion efficiency (blue column) (d) of TBCF-1.5.

sample, the water evaporation rate is significantly enhanced in the presence of the BCF. The BCF has a water evaporation rate of $1.26 \mathrm{~kg} \mathrm{~m}^{-2} \mathrm{~h}^{-1}$, about 2.7 times higher than that of pure water $\left(0.46 \mathrm{~kg} \mathrm{~m}^{-2} \mathrm{~h}^{-1}\right)$ as shown in Fig. $5 b$, indicating that the BCF is an efficient PTC material generating solar vapor due to its excellent solar absorption ability. Among TBCF series, TBCF-1.5 shows the highest water evaporation rate $\left(1.47 \mathrm{~kg} \mathrm{~m}^{-2} \mathrm{~h}^{-1}\right)$ and solar-vapor conversion efficiency $(92.5 \%)$ in a controlled period of time. The evaporation rate of water and the solar-vapor conversion efficiency increases with TiN deposition amount when TiN deposition amount is lower than $1.5 \mathrm{mg}$. However, when TiN deposition amount is over $1.5 \mathrm{mg}, 2.0$ and $4.0 \mathrm{mg}$, the evaporation rate of water and the solar-vapor conversion efficiency decreases though they have higher solar absorption, because the 

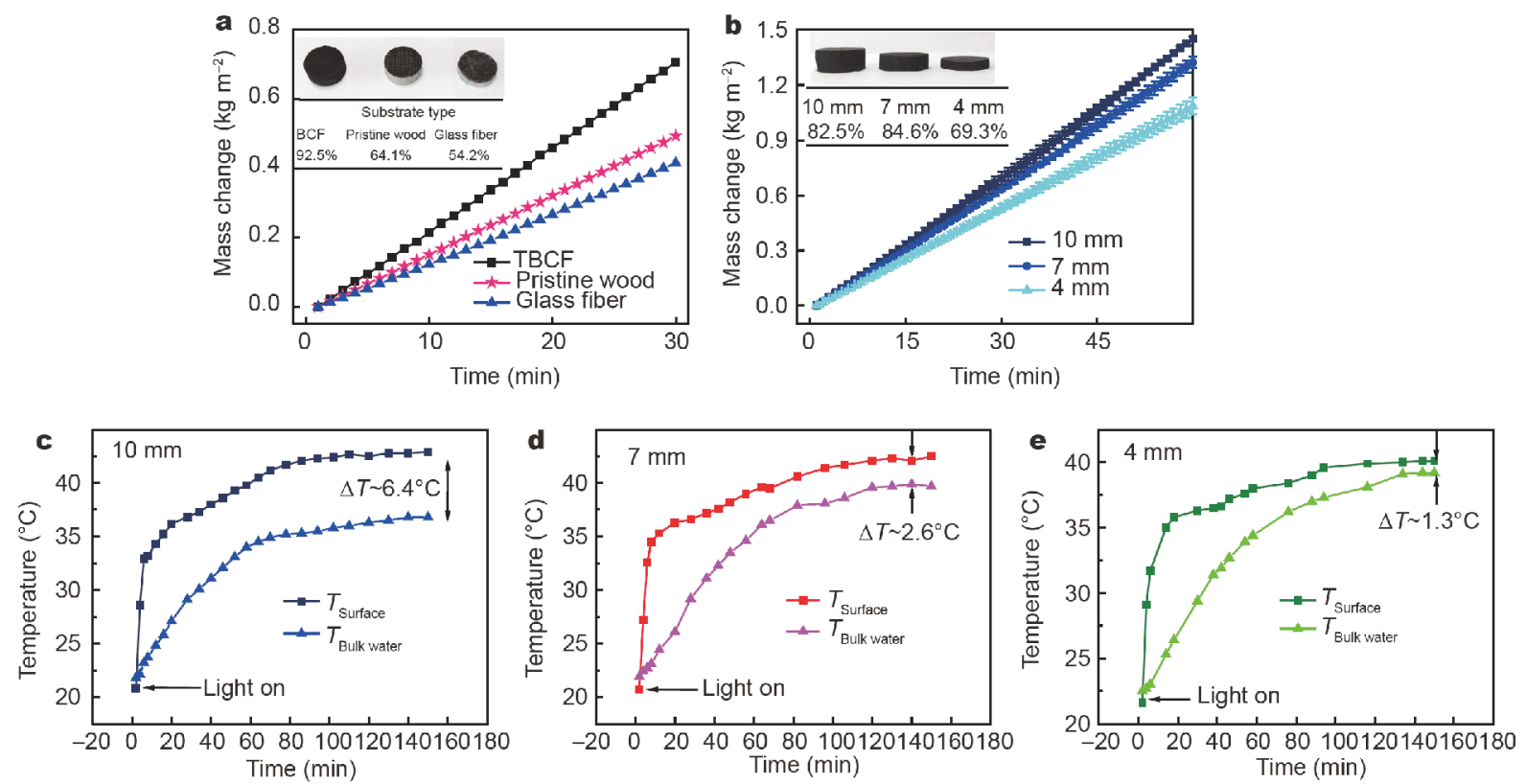

Figure 6 Solar evaporation performance of TiN on different substrates: (a) Water mass changes-time curve of different samples with 1.5 mg TiN on BCF, pristine wood and glass fiber under 1-sun. Inset is the optical images and solar-vapor conversion efficiencies of these samples; (b) water mass changes-time curve of TCBF-1.5 with different substrate thickness. Inset is the optical images and solar-vapor conversion efficiencies of these samples; (c-e) Surface and bulk water temperature as a function of time of TBCF-1.5 with different substrate thickness of 10, 7 and 4 mm.

solar vapor generation behavior is influenced not only by solar absorption but also by TiN film structure. TiN film becomes dense with increasing TiN deposition amount, which not only impedes the transport of water to top surface, but also reduces the contact area of the water molecules with TiN NPs. Fig. $5 \mathrm{c}$ and $\mathrm{d}$ indicates that the evaporation rate and the solar-vapor conversion efficiency of TBCF-1.5 decreases very slightly after 5 cycles, demonstrating its good reusability.

Fig. 6 shows the dependence of the solar evaporation performance of the hybrid materials on the substrate. Fig. 6a shows that when $1.5 \mathrm{mg}$ TiN NPs are deposited on $10 \mathrm{~mm}$ glass-fiber cotton and $10 \mathrm{~mm}$ pristine wood, they exhibit solar-vapor conversion efficiencies of $54.2 \%$ and $64.1 \%$, respectively, much lower than $92.5 \%$ of TBCF-1.5. Especially, The BCF has a solar-vapor conversion efficiency of $73.5 \%$ as shown in Fig. 5b. These results indicate that the BCF is an outstanding and promising substrate because of numerous aligned microchannels for fast water transport, low thermal conductivity along the channel direction and excellent solar-thermal performance. When $1.5 \mathrm{mg}$ TiN NPs are deposited on different thicknesses of BCF substrates, respectively, these samples exhibit different evaporation rates of water and conversion efficiencies $(\eta)$ as shown in Fig. 6b. The samples with substrate thicknesses of 4, 7 and $10 \mathrm{~mm}$ have conversion efficiencies of $69.3 \%, 84.6 \%$ and $92.5 \%$ respectively, indicating that the conversion efficiency increases with the thickness of the substrate due to the enhanced heat-insulation performance, which is further confirmed by the temperature-time curves as shown in Fig. $6 c-e$. The surface water temperature rises rapidly once the simulated solar light irradiates the sample for the first 8-15 min, and then the temperature rises slowly for next $60 \mathrm{~min}$ up to a stable temperature. However, the bulk water temperature rises slowly up to a stable temperature when the simulated solar light irradiates the sample. The steady state temperature differences between surface water and bulk water for 4,7 and $10 \mathrm{~mm}$ substrates are $1.3,2.6$ and $6.4^{\circ} \mathrm{C}$, respectively, indicating that the more thickness the substrate is, the higher heat-insulation performance it exhibits.

\section{CONCLUSIONS}

In summary, TiN NPs are successfully deposited on BCF, which exhibits an excellent solar-steam-generation performance. The rate of water evaporation and the solarvapor conversion efficiency are related to the amount of TiN NPs and the thickness of the BCF substrate. A solarvapor conversion efficiency of $92.5 \%$ is obtained under 1Sun simulated solar irradiation, the highest efficiency among the reported wood-based materials. Because of its 
easy preparation, low cost, non-toxicity, good reusability and high efficiency, the device will be a promising solar conversion material in desalination, sewage treatment and many other applications.

\section{Received 24 July 2018; accepted 7 September 2018;} published online 15 October 2018

1 Yang X, Liu W, Ren P. All solid-state solar cells based on $\mathrm{CH}_{3}$ $\mathrm{NH}_{3} \mathrm{PbI}_{3}$-sensitized $\mathrm{TiO}_{2}$ nanotube arrays. Phys E-Low-dimensional Syst Nanostruct, 2016, 83: 322-328

2 Pan S, Liu X, Guo M, et al. Engineering the intermediate band states in amorphous $\mathrm{Ti}^{3+}$-doped $\mathrm{TiO}_{2}$ for hybrid dye-sensitized solar cell applications. J Mater Chem A, 2015, 3: 11437-11443

3 Guo K, Li M, Fang X, et al. Enhancement of properties of dyesensitized solar cells by surface plasmon resonance of Ag nanowire core-shell structure in $\mathrm{TiO}_{2}$ films. J Mater Chem A, 2013, 1: 7229_ 7234

4 Liu P, Zhao Y, Qin R, et al. Photochemical route for synthesizing atomically dispersed palladium catalysts. Science, 2016, 352: 797800

5 Rtimi S, Baghriche O, Sanjines R, et al. Photocatalysis/catalysis by innovative TiN and TiN-Ag surfaces inactivate bacteria under visible light. Appl Catal B-Environ, 2012, 123-124: 306-315

6 Yang CC, Yu YH, van der Linden B, et al. Artificial photosynthesis over crystalline $\mathrm{TiO}_{2}$-based catalysts: fact or fiction? J Am Chem Soc, 2010, 132: 8398-8406

7 Siva Reddy V, Kaushik SC, Ranjan KR, et al. State-of-the-art of solar thermal power plants-A review. Renew Sustain Energy Rev, 2013, 27: 258-273

8 M C, Yadav A. Water desalination system using solar heat: A review. Renew Sustain Energy Rev, 2017, 67: 1308-1330

9 Eltawil MA, Zhengming Z, Yuan L. A review of renewable energy technologies integrated with desalination systems. Renew Sustain Energy Rev, 2009, 13: 2245-2262

10 Liu Y, Lou J, Ni M, et al. Bioinspired bifunctional membrane for efficient clean water generation. ACS Appl Mater Interfaces, 2016, 8: $772-779$

11 Neumann O, Neumann AD, Silva E, et al. Nanoparticle-mediated, light-induced phase separations. Nano Lett, 2015, 15: 7880-7885

12 Neumann O, Urban AS, Day J, et al. Solar vapor generation enabled by nanoparticles. ACS Nano, 2013, 7: 42-49

13 Ghasemi H, Ni G, Marconnet AM, et al. Solar steam generation by heat localization. Nat Commun, 2014, 5: 4449

14 Bae K, Kang G, Cho SK, et al. Flexible thin-film black gold membranes with ultrabroadband plasmonic nanofocusing for efficient solar vapour generation. Nat Commun, 2015, 6: 10103

15 Zhou L, Tan Y, Ji D, et al. Self-assembly of highly efficient, broadband plasmonic absorbers for solar steam generation. Sci Adv, 2016, 2: e1501227-e1501227

16 Zhou L, Tan Y, Wang J, et al. 3D self-assembly of aluminium nanoparticles for plasmon-enhanced solar desalination. Nat Photonics, 2016, 10: 393-398

17 Zhou L, Zhuang S, He C, et al. Self-assembled spectrum selective plasmonic absorbers with tunable bandwidth for solar energy conversion. Nano Energy, 2017, 32: 195-200

18 Zielinski MS, Choi JW, La Grange T, et al. Hollow mesoporous plasmonic nanoshells for enhanced solar vapor generation. Nano Lett, 2016, 16: 2159-2167
19 Ren P, Yang X. Synthesis and photo-thermal conversion properties of hierarchical titanium nitride nanotube mesh for solar water evaporation. Sol RRL, 2018, 2: 1700233

20 Wang $\mathrm{X}, \mathrm{He} \mathrm{Y}$, Cheng G, et al. Direct vapor generation through localized solar heating via carbon-nanotube nanofluid. Energy Convers Manage, 2016, 130: 176-183

21 Ito Y, Tanabe Y, Han J, et al. Multifunctional porous graphene for high-efficiency steam generation by heat localization. Adv Mater, 2015, 27: 4302-4307

22 Li Y, Gao T, Yang Z, et al. 3D-printed, all-in-one evaporator for high-efficiency solar steam generation under 1 sun illumination. Adv Mater, 2017, 29: 1700981

23 Sajadi SM, Farokhnia N, Irajizad P, et al. Flexible artificially-networked structure for ambient/high pressure solar steam generation. J Mater Chem A, 2016, 4: 4700-4705

24 Ding H, Peng G, Mo S, et al. Ultra-fast vapor generation by a graphene nano-ratchet: a theoretical and simulation study. Nanoscale, 2017, 9: 19066-19072

25 Li X, Xu W, Tang M, et al. Graphene oxide-based efficient and scalable solar desalination under one sun with a confined 2D water path. Proc Natl Acad Sci USA, 2016, 113: 13953-13958

26 Wang J, Li Y, Deng L, et al. High-performance photothermal conversion of narrow-bandgap $\mathrm{Ti}_{2} \mathrm{O}_{3}$ nanoparticles. Adv Mater, 2017, 29: 1603730

27 Ye M, Jia J, Wu Z, et al. Synthesis of $\mathrm{Black}^{\mathrm{TiO}_{x}}$ nanoparticles by $\mathrm{Mg}$ reduction of $\mathrm{TiO}_{2}$ nanocrystals and their application for solar water evaporation. Adv Energy Mater, 2017, 7: 1601811

28 Chen C, Zhou L, Yu J, et al. Dual functional asymmetric plasmonic structures for solar water purification and pollution detection. Nano Energy, 2018, 51: 451-456

29 Wang X, He Y, Liu X, et al. Solar steam generation through bioinspired interface heating of broadband-absorbing plasmonic membranes. Appl Energy, 2017, 195: 414-425

$30 \mathrm{Xu} \mathrm{W}, \mathrm{Hu} \mathrm{X}$, Zhuang $\mathrm{S}$, et al. Flexible and salt resistant Janus absorbers by electrospinning for stable and efficient solar desalination. Adv Energy Mater, 2018, 8: 1702884

31 Wang G, Fu Y, Ma X, et al. Reusable reduced graphene oxide based double-layer system modified by polyethylenimine for solar steam generation. Carbon, 2017, 114: 117-124

32 Li X, Lin R, Ni G, et al. Three-dimensional artificial transpiration for efficient solar waste-water treatment. Natl Sci Rev, 2018, 5: 7077

$33 \mathrm{Hu} \mathrm{X}, \mathrm{Xu} \mathrm{W}$, Zhou L, et al. Tailoring graphene oxide-based aerogels for efficient solar steam generation under one sun. Adv Mater, 2017, 29: 1604031

34 Ren $\mathrm{H}$, Tang $\mathrm{M}$, Guan B, et al. Hierarchical graphene foam for efficient omnidirectional solar-thermal energy conversion. Adv Mater, 2017, 29: 1702590

35 Zhao F, Zhou X, Shi Y, et al. Highly efficient solar vapour generation via hierarchically nanostructured gels. Nat Nanotechnol, 2018, 13: 489-495

36 Mahltig B, Swaboda C, Roessler A, et al. Functionalising wood by nanosol application. J Mater Chem, 2008, 18: 3180

37 Zhu H, Jia Z, Chen Y, et al. Tin anode for sodium-ion batteries using natural wood fiber as a mechanical buffer and electrolyte reservoir. Nano Lett, 2013, 13: 3093-3100

38 Zhu M, Song J, Li T, et al. Highly anisotropic, highly transparent wood composites. Adv Mater, 2016, 28: 5181-5187

39 Sehaqui H, Zhou Q, Berglund LA. Nanostructured biocomposites of high toughness-a wood cellulose nanofiber network in ductile 
hydroxyethylcellulose matrix. Soft Matter, 2011, 7: 7342-7350

40 Xue G, Liu K, Chen Q, et al. Robust and low-cost flame-treated wood for high-performance solar steam generation. ACS Appl Mater Interfaces, 2017, 9: 15052-15057

41 Liu KK, Jiang Q, Tadepalli S, et al. Wood-graphene oxide composite for highly efficient solar steam generation and desalination. ACS Appl Mater Interfaces, 2017, 9: 7675-7681

42 Chen C, Li Y, Song J, et al. Highly flexible and efficient solar steam generation device. Adv Mater, 2017, 29: 1701756

43 Zhu M, Li Y, Chen F, et al. Plasmonic wood for high-efficiency solar steam generation. Adv Energy Mater, 2018, 8: 1701028

$44 \mathrm{Xu} \mathrm{N}, \mathrm{Hu} \mathrm{X}, \mathrm{Xu} \mathrm{W}$, et al. Mushrooms as efficient solar steamgeneration devices. Adv Mater, 2017, 29: 1606762

$45 \mathrm{Li} \mathrm{X}, \mathrm{Li} \mathrm{J}, \mathrm{Lu} \mathrm{J}$, et al. Enhancement of interfacial solar vapor generation by environmental energy. Joule, 2018, 2: 1331-1338
46 Guler U, Shalaev VM, Boltasseva A. Nanoparticle plasmonics: going practical with transition metal nitrides. Mater Today, 2015, 18: $227-237$

47 Zhang J, Chen TP, Li XD, et al. Investigation of localized surface plasmon resonance of $\mathrm{TiN}$ nanoparticles in $\mathrm{TiN}_{x} \mathrm{O}_{y}$ thin films. Opt Mater Express, 2016, 6: 2422

Author contributions Guo D performed the experiments and wrote the manuscript. Yang $\mathrm{X}$ designed the experiments and revised the manuscript. Both authors contributed to the general discussion.

Conflict of interest The authors declare no conflict of interest.

Supplementary information Supporting data are available in the online version of the paper.

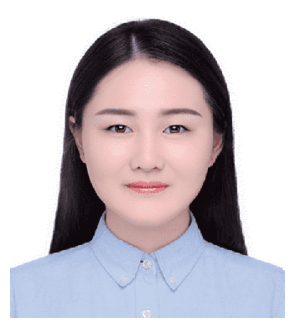

Dongfang Guo received her bachelor degree from Tongji University. She is now a master candidate at Tongji University and her research focuses on PTC materials.

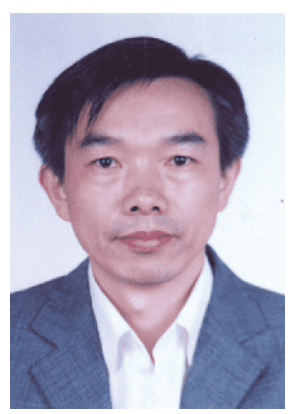

Xiuchun Yang received his $\mathrm{PhD}$ degree from Zhejiang University in 1996. After two years of post-doctor research at the University of Science and Technology Beijing, he obtained a position of visiting scholar in Clausthal University of Technology and Martin-Luther University Halle, Germany. He carried out research on the syntheses, characterizations and photoelectron-chemical and photo-thermal properties of low-dimension materials and nanocomposites.

\section{基于低成本TiN/生物碳泡沫的高效太阳能蒸汽发生器}

郭东方 $^{1}$, 杨修春 $^{1,2^{*}}$

摘要 利用太阳能产生蒸汽是净化污水或海水的有效方法. 本文中, 我们将氮化钛纳米颗粒沉积在经过碳化处理的木块上, 得到一种新型 的双层太阳能蒸汽发生材料. TiN纳米颗粒具有比以往报道过的光热转换材料(如等离子体金属、碳基材料和半导体纳米材料)更好的稳 定性、更经济的价格、更低的毒性、更宽和更强的光吸收等多重优点. TiN纳米颗粒的沉积量以及基底的厚度和类型对水的蒸发速率和 太阳能-蒸汽转换效率有重要影响. 在模拟太阳光强度为 $1 \mathrm{~kW} \mathrm{~m}^{-2}$ 下, 该材料具有 $92.5 \%$ 的太阳能-蒸汽转换效率, 这是已知的木基光热转 换材料中的最高效率. 此外, 该材料具有良好的可重复利用性. 